\title{
The Research of Cooling Tower Scale in HVDC Convertor Valve Cooling System
}

\author{
Xin ZHENG, Dehui PENG \\ EHV Transmission Company of China Southern Power Grid Co., Ltd. Guangzhou, China
}

Yuliang WEN, Zhimin LU, Shaojun YANG

Guangzhou Goaland Energy Conservation Tech.Co., Ltd., Guangzhou, China

\begin{abstract}
Through the site investigation, design a set of test apparatus used to study the cooling tower scale problem in HVDC valve cooling system, integrating the scale of more mature process on this device, through on-site validation test method to inspect the scale inhibition effect on the cooling tower in HVDC valve cooling system. Results show that the selected membrane desalination technology has great technical advantages.
\end{abstract}

KEYWORD: Anti-scaling technology; HVDC convertor valve; water cooling system; scale

\section{GENERAL INSTRUCTIONS}

HVDC thyristor converter valve cooling system is consist of internal circulation and outside circulation: the system with the cooling medium recirculating inside the valve parts for cooling is known as the internal circulaiton, while the function of outside circulation is to transfer heat to atmosphere.

In the operation process of the cooling tower, spray water evaporation and concentration, continuously increase the water hardness, and on the surface of heat-transferring coil, the $\mathrm{Ca}\left(\mathrm{HCO}_{3}\right)_{2}$ easily decomposed to generate the undissolved $\mathrm{CaCO}_{3}$, the insoluble material adsorption on the surface of heat-transferring coil, as time passes, dirt become firmly.

On the heat exchange equipment, every $1 \mathrm{~mm}$ scale increase will make the heat exchange efficiency reduce about 10\% 20\%[1]. The scaling of cooling tower will decrease the heat exchange efficiency of valve cooling system, and also cause corrosion under the scale. Solving the problem of fouling in cooling tower to ensure the safe and stable in HVDC valve cooling system is of great significance.

\section{SITE INVESTIGATION}

To comprehensively understand the fouling characteristics of cooling tower, some sample from converter stations is collected, and analyzed the dirt component by the EDS spectrometer, the test results are as follows:

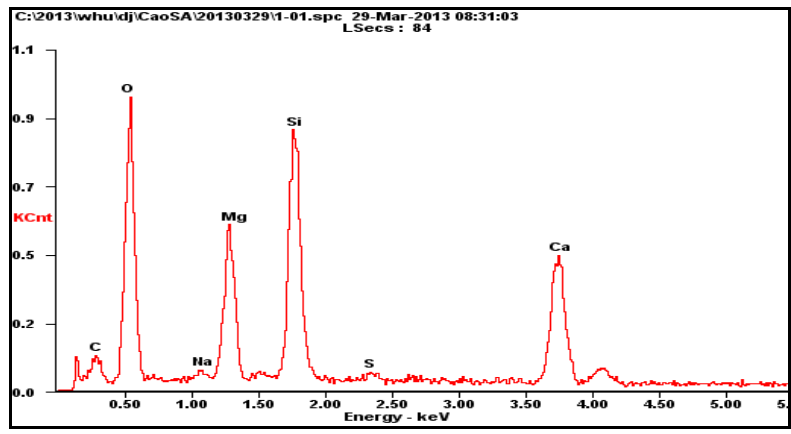

Fig. 1 Xingren station

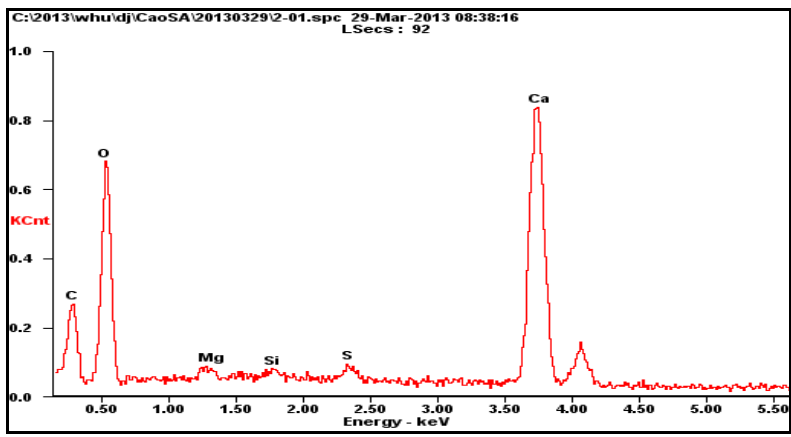

Fig. 2 Tianshengqiao station

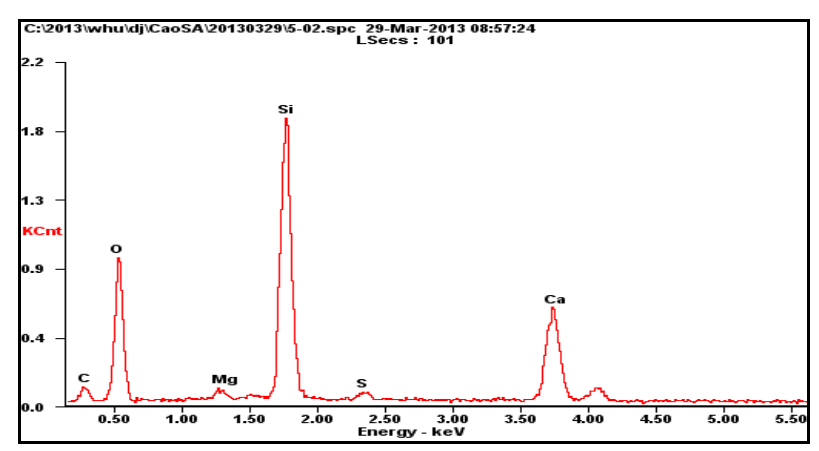

Fig. 3 Baoan station 


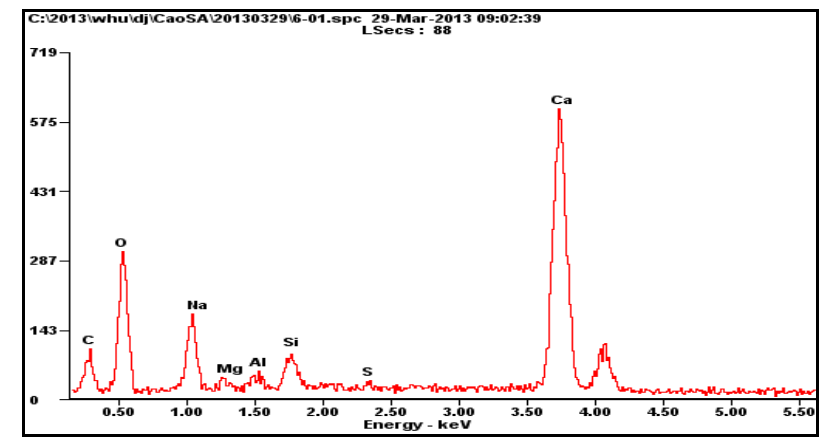

Fig. 4 Chuxiong station

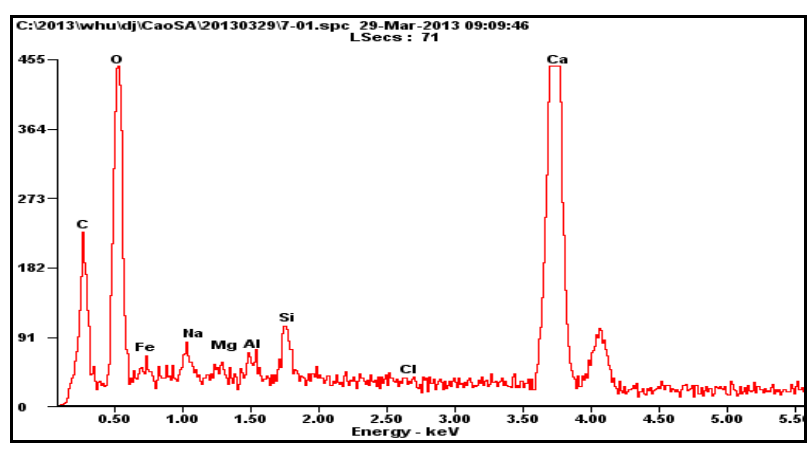

Fig. 5 Zhaoqing station

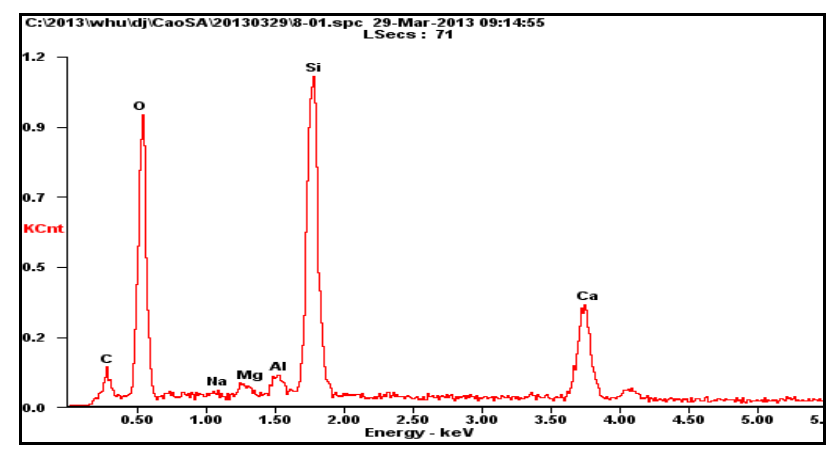

Fig. 6 Suidong station

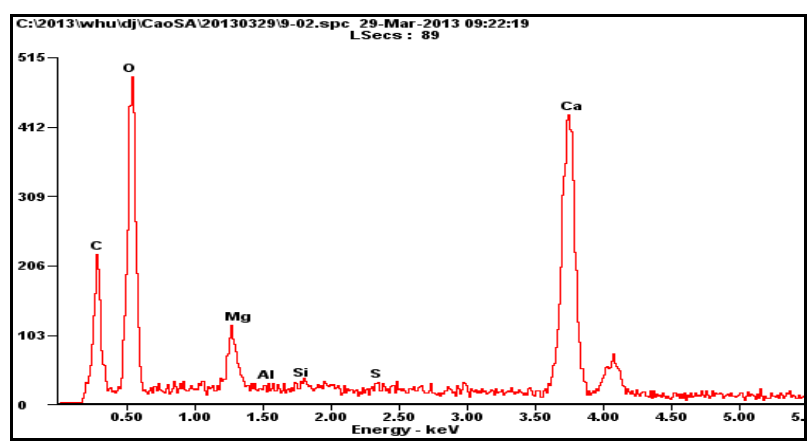

Fig. 7 Anshun station

From the spectrum diagram, we can see that in the dirt of the various stations, C、O、Ca element content are in the majority, the main component of the dirt in is $\mathrm{CaCO}_{3}$, some stations have $\mathrm{Mg}$ and $\mathrm{Si}$, meaning that the dirt contains $\mathrm{Mg}(\mathrm{OH})_{2}$ and $\mathrm{SiO}_{2}$.

In zhaoqing station the dirt contains a certain amount of Fe, which is caused by coil corrosion, and oxidizing bactericide will bound to result in a Fe$(\mathrm{OH})_{3}$ large deposits, and bactericide effect will be greatly reduced.
In conclusion: By investigation we believe that to find out the method of solving problem of fouling, it is necessary to do field test.

\section{EQUIPMENT}

Combined with site investigation results the test apparatus is designed as shown in figure 8

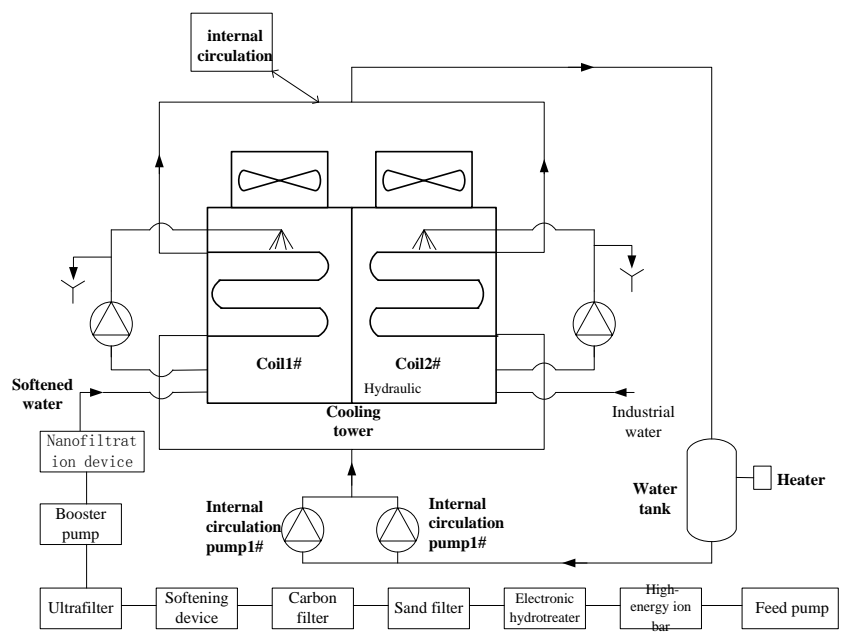

Fig. 8 Process diagram of the experiment device

The equipment collects three electromagnetic anti-scaling technologies, resin softening anti-scaling technology and coating technology, etc. Electromagnetic anti-scaling technology including high-energy ion bar, electronic hydrotreater, shui liqing[2].

The test device is composed of two parts, respectively are anti-scaling technology integrated device and cooling tower simulator. The inlet water through anti-scaling technology integration device comes from the industrial pool, and outlet water goes to cooling tower 1 \#. The 2 \# cooling tower is directly connected with the industrial pool, with clapboard put in the middle of 1 \# and 2 \#. The two cooling towe have the same function and stucture and relatively independent, perfectly meet the requairment of anti-scaling contrast test.

\section{EXPERIMENT OF HIGH-ENERGY ION BAR}

High-energy ion bar is a pipe shape "static scale controller" [3]. The principle of anti-scaling of Highenergy ion is through the release of high voltage electrostatic field, the water molecules arranged in chain neatly and in order according to the positive and negative, hydrated ion of anion and cation are lined up in positive negative order, thus they cannot move freedom in the water of dipole, and prevent $\mathrm{Ca}^{2+}, \mathrm{Mg}^{2+}$ trend to the wall, purpose of scale and antiscale achieved. On the other hand the high voltage electrostatic field can make the association 
into a single water molecules, water molecules polarized, dipole moment incerased, which aggrandize the polarity. Polarization of water molecules can be strongly adsorbed scale ion of anion and cation in the water, stoping the ion of anion and cation aggregate into scale[4].
As the high-energy ion bar cannot be installed on the coil, so the device was installed on the inlet of cooling tower to test the descaling effect of outlet water. And install a pipeline which internal has scaled after the pipe of high-energy ion bar, open the high-energy ion, and every two days to take a sample test. The results obtained, as shown in table1:

Table 1 Analysis of high-energy ion bar process scale effect

\begin{tabular}{|c|c|c|c|c|c|c|c|c|}
\hline Hardness mg/L & first & second & third & forth & fifth & sixth & seventh & eighth \\
\hline Industrial water & 51.70 & 47.36 & 47.79 & 49.10 & 45.4 & 51.70 & 52.47 & 54.63 \\
\hline Treated water & 52.57 & 52.14 & 50.83 & 52.57 & 55.8 & 48.01 & 50.73 & 52.90 \\
\hline
\end{tabular}

Results show that in the first five sampling, the hardness of output water is higher than that of industrial water, and then in the next three sampling, the hardness of output water is slightly lower than that of industrial water, it means that in the electric field of high-energy ion bar, dirt removal effect is not stable, appling to HVDC valve cooling system has some limitations.

\section{EXPERIMENT OF ELECTRONIC HYDROTREATER}

The mechanism of the electronic hydrotreater is that when frequency variable electric current through the winding coil, vertical magnetic field generated between the pipe wall and the coil, then the water will through the pipe cutting magnetic induction line, the device works. The internal structure of electronic hydrotreateras[5] shown in figure 9:

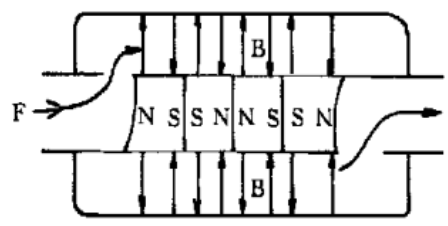

Fig. 9 The internal structure of electronic hydrotreater
Now the researches on the mechanism of the magnetic field anti-scaling are mainly concentrated on the influence of magnetic treatment to the content of dissolved gas in water, moisture substructure, surface tension of liquid, $\mathrm{pH}$, the nucleation rate, zeta potential of the ion of anion and cation, the crystallization morphology etc.[6]

The universal opinions is when water through the electronic water processor, it was effected by loren magnetic, the ion of anion and cation run in different directions, the risk of a collision reduced, or ions combine to generate aragonite which has no adhesive ability. On the other hand, influenced by the magnetic field, water molecule dipole distance increases, therefore it can effectively weaken the dirt intermolecular forces between the wall and the adhesion, then dirt dissolved and peeling off gradually, thereby, scaling inhibition function achieved.

Similar to high-energy ion bar, electronic water processor cannot direct effects on heat exchange coil, so the experimental method is the same as highenergy ion bar to test the descaling effect of outlet water. Install a pipeline which internal has scaled after the pipe of electronic hydrotreater. Then open electronic hydrotreater, and every two days to take a sample test. Results are shown in the table 2.

Table 2 Analysis of electronic hydrotreater process scale effect

\begin{tabular}{|l|l|l|l|l|l|l|l|l|}
\hline Hardness mg/L & first & second & third & forth & fifth & sixth & seventh & eighth \\
\hline Industrial water & 51.70 & 47.36 & 47.79 & 49.10 & 45.4 & 51.70 & 52.47 & 54.63 \\
\hline Treated water & 50.40 & 51.70 & 50.40 & 53.01 & 51.1 & 43.66 & 51.16 & 52.47 \\
\hline
\end{tabular}

Results show that except the sixth sample, the rest of the 7 samples has no big difference on hardness compared with industrial water, and also difficult to distinguish the scale inhibition effect, put the first batch of samples for discription, the results show that the effect of electronic hydrotreater is not stable, which means that the device should not be used in HVDC valve cooling system.

\section{EXPERIMENT OF MEMBRANE DESALINATION TECHNOLOGY}

Membrane desalination technology (also called membrane filtration technology) refers to the method using membrane selective permeation, under the impetus of the outside energy or chemical potential difference to achieve the gola of mixture of solute 
separation, classification, purification and concentration[7]. The membrane desalination membrane mainly used by nano-filtration (NF) and reverse osmosis (RO), this experiment is given priority to with nano-filtration membrane.

First close the high-energy ion bar and electronic hydrotreater, open the shui liqing, softening device and nano-filtration system, connect the outlet coupling of the anti-scaling technology integration device to the cooling tower 1 \#, use the float liquid level gauge to control the amount of water. Connect the industrial connection pool with cooling tower 2 \#, and control the water level by float valve.
To simulate cooling process of valve cooling system, some special equipment are added on the basis of the device, such as buffer tank, and 4 sets of heater which the power is $15 \mathrm{kw}$ to control the inner circulating water temperature.

At the beginning of the experiment, adjust the circulating water temperature and flow rate, spray water flow and abandon conditions, make sure that the test apparatus is consistent with the relevant data of the normal operation of valve cooling system.

Test conditions set as shown in table 3:

Table 3 Parameters of experiment

\begin{tabular}{|c|c|c|c|c|c|}
\hline Innnerflow $1 / \mathrm{min}$ & $\begin{array}{c}\text { Inlet } \\
\text { temperature } /{ }^{\circ} \mathrm{C}\end{array}$ & $\begin{array}{c}\text { Outlet } \\
\text { temperature } /{ }^{\circ} \mathrm{C}\end{array}$ & Input power/kW & $\begin{array}{c}\text { Spray } \\
\text { flow/l/min }\end{array}$ & $\begin{array}{c}\text { Abandon } \\
\text { amount } / \mathrm{l} / \mathrm{min}\end{array}$ \\
\hline 112 & $48.5 \sim 49.5$ & $41.5 \sim 42.5$ & 60 & 185 & 0.25 \\
\hline
\end{tabular}

During the trial, collect industrial water, nanofiltration outlet water, catchment water of $1 \#$ and $2 \#$ cooling tower to make analysis, and record the cooling coil fouling conditions. Two days a sample.
By analysize the content of various ions of Industrial water and nano-filtration outlet water to inspect the effect of nano-filtration desalination. Selection of desalination plant operation is the most stable data set, the results as shown in table 4:

Table 4 Analysis of Nano-filtration desalination effect

\begin{tabular}{|l|l|l|l|l|l|l|l|l|l|}
\hline $\mathrm{mg} / \mathrm{L}$ & hadness & $\mathrm{Cl}^{-}$ & $\mathrm{NO}_{3}^{-}$ & $\mathrm{SO}_{4}{ }^{2-}$ & $\mathrm{Ca}^{2+}$ & $\mathrm{Mg}^{2+}$ & conductivity & total alkalinity & $\mathrm{pH}$ \\
\hline Treated water & - & 1.01 & 4.53 & 1.29 & - & - & 41.70 & 20.70 & 6.75 \\
\hline Industrial water & 194.19 & 7.83 & 16.99 & 51.74 & 51.70 & 15.81 & 438.00 & 260.30 & 7.80 \\
\hline Salt rejection rate & - & $87.11 \%$ & $73.35 \%$ & $97.51 \%$ & - & - & $90.48 \%$ & $92.05 \%$ & - \\
\hline
\end{tabular}

The table shows that when industrial water passed through the filter processing, the total hardness is lower than offline detection of total hardness referencing the standard of GB5750-85 drinking water standard test, the detection limit is $1 \mathrm{mg} / \mathrm{L}$, namely the hardness of nano-filtration outlet water is less than $1 \mathrm{mg} / \mathrm{L}$, hardness removal rate is more than $99.5 \%$. While other ions removal rate is low, and the tolel desalination rate is about $90 \%$.

By testing the water quality of cooling tower water pan and coil surface condition to observe scale inhibition effect of membrane desalination. Pick up water samples, when the device work stable and analysis the hardness for reference index, the test results as shown in table 5:

Table 5 Hardness value of spray water

\begin{tabular}{|c|c|c|c|c|c|}
\hline $\begin{array}{c}\text { Hardness } \\
\left(\mathrm{CaCO}_{3}\right) \mathrm{mg} / \mathrm{L}\end{array}$ & first & second & third & forth & fifth \\
\hline Water of tower 1\# & 2.17 & 1.18 & 1.09 & 1.5 & 1.27 \\
\hline Water of tower 2\# & 212.63 & 414.42 & 263.62 & 266.3 & 236.50 \\
\hline
\end{tabular}

The table shows that after evaporation concentration, spray water in tower1\# is still much smaller in hardness compared with spray water in tower 2 \#. Only spray water in tower 1 \# concentrate at least 190 times can reach the hardness value of spray water in tower 2 \# on average.

Combine the above data with conductivity, temperature, total alkalinity, $\mathrm{PH}$, etc do langelier saturation index calculation ${ }^{[8]}$, the temperature of inner loop water is $48^{\circ} \mathrm{C}$, the results as shown in table 6:

Table 6 Calculation result of Langelier Saturation index

\begin{tabular}{|c|c|c|c|c|c|}
\hline $\begin{array}{c}\text { Langelier saturation } \\
\text { index }\end{array}$ & first & second & third & forth & fifth \\
\hline Water of tower 1\# & -0.96 & -1.45 & -1.75 & -1.59 & -1.53 \\
\hline Water of tower 2\# & 1.73 & 2.39 & 2.34 & 2.37 & 2.23 \\
\hline
\end{tabular}

The results showed that Langelier saturation index of spray water in tower 1 \# is less than 0 , while saturation index of spray water in tower 2 \# were more than 0 , refer to the correlation theory, 1 \# 
coil will not appear fouling phenomenon, 2 \# tower coil will appear serious scaling phenomenon.

After 20 days, we observe the coil surface dirt situation as shown in the figure below:

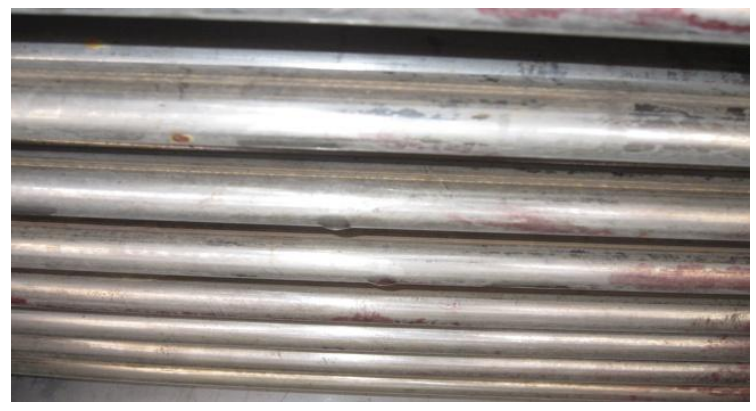

Fig.10 Surface condition of coil 1\#

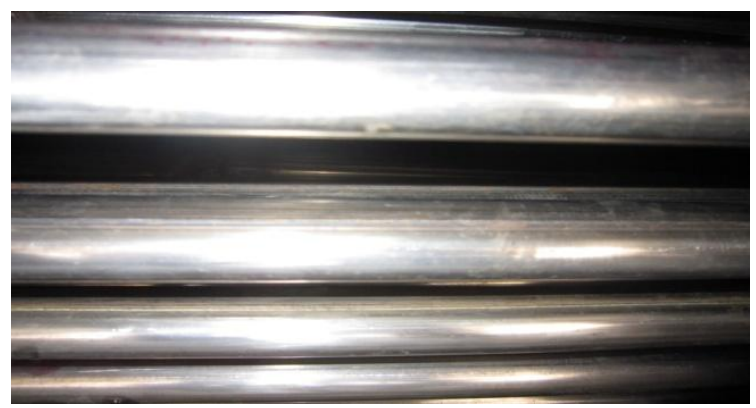

Fig.11 Surface condition of coil 2\#

From the picture you can see, 1 \# coil surface is bright and clean without sundry, 2 \# coil was in the clear dirt grain surface. When touch it, 1 \# coil surface smooth like new, 2 \# coil surface has obvious rough feeling, it means that on the surface of 2 \# coil scale has been formed.

Through the experiment it can be proved that using membrane desalination anti-scaling technique can effectively restrain the generation of cooling coil surface dirt, and in a certain range, can reduce the anmout of abandoned water, increase the concentration ratio of spray water, save water resource effectively.

\section{CONCLUSION}

Through the experiment, the following conclusions can be obtained:

(1)In the object as the water pipe, electromagnetic treatment and high voltage electrostatic treatment has may have great scale inhibition effect, but this research project is subject to the object of study, that is high-energy ion bars and high-voltage electrostatic field can only choose in the water pipe installation position, can't install on the heat exchange coil, and after the experiment, in the location of the equipment scale inhibition effect on the coil is not stable, so it is unsuitable to use in the valve cooling system. Shui liqing is a kind of anti-scaling equipment, low-voltage electrostatic field can take the initiative to reduce the water hardness and alkalinity, which is called the active anti-scaling technology[9]. But in the district where hardness of water is high, it too often to clean the device in the converter station, which lack of convenience.

(2) Using nano-filtration membrane desalination technology of scale inhibitor has good scale inhibition effect, if the waters treatment process is used in converter station, it will completely solve the problem of fouling in cooling tower, effective guarantee for the stable operation of the valve cooling system.

(3) The traditional dosing process import more organic components, which will increase of COD content in water, and the easy degradation ingredient can make the propagation of microbes, leading to deterioration of water quality. Membrane desalination anti-scaling technique can effectively avoid the above problems.

\section{ACKNOWLEDGEMENT}

The authors may acknowledge the science fund of Guangdong provincial department of science and technology, No.2012A090100005.

\section{REFERENCES}

[1] Jiaomei Jiang. (2004), Preliminary research of metastable zone of calcium carbonate scale formation in the circulating cooling water, Nanjing University of Technology, Master's degree thesis of Nanjing university of technology.

[2] Feng Chen, Boming Zhu,Zhongqin Li. Shui liqing reduction water electrolysis technology in the application of circulating water treatment. Refrigeration. 2009; 28(4): 24 29.

[3] Dejun Wu, Liqing Tian,Guoyao Mao. Status quo of electrostatic water treatment. Industrial water treatment. 1982 (2): 17 21.

[4] Xianxin Zhu, Hong Yang,Tianrui Wang. Research status of electrostatic water treatment technology. China Environmental Protection Industry. 2006 (5):37 39.

[5] Luo man, Lu zhu. Anti-scaling research of magnetic field treated water. water treatment technology. 2000; 26(4): 218 221.

[6] XiaomingGong, Honghua Ge,RuiLiu. Research of scale inhibition mechanism and application of magnetic field treatment of water. industrial water treatment. 2010; 30(8): 10 .

[7] Murong Ge, Li Xu, Xianyou Zeng,etc. The research progress of nanofiltration theory. fluid machinery. 2005; 33(1): 35 39.

[8] Yushan Cheng, Huiwu Xu,Rongjiang Liu,etc. Calculation method research of saturation index and stability index . Cleaning World. 2012;28(9):17 21.

[9] Zhenhua Quan, Yonghchang Chen, Yunjie Liu ,etc. The comparison of physical anti-scaling technique in the circulating cooling water. Industrial Water \& Wastewater. 2008; 39(3):72 75. 